\title{
Transformation of Local Leadership- Narratives on changed Interaction
}

\author{
Arto Haveri, Jenni Airaksinen, Henna Paananen \\ School of Management, University of Tampere, Tampere, Finland \\ Email: arto.haveri@uta.fi
}

Received 24 September 2015; accepted 22 November 2015; published 25 November 2015

Copyright (C) 2015 by authors and Scientific Research Publishing Inc.

This work is licensed under the Creative Commons Attribution International License (CC BY). http://creativecommons.org/licenses/by/4.0/

c) (i) Open Access

\begin{abstract}
This article investigates the transformation of local government leadership as a change in interaction. Traditional interaction patterns are challenged by the increasing complexity of governance relations. The empirical analysis is based on biographical narratives of very experienced (born in 1945-1950) Finnish municipal chief executive officers. The narratives form a rich set of interpretations about the changes that have occurred in the role of municipalities during the last four decades. According to the narratives, both the quantity and quality of interaction have changed markedly: interaction is needed at numerous surfaces, but the quality of interaction is undergoing alteration. The current trend of instant interaction requires more situational awareness, social skills and quicker responses.
\end{abstract}

\section{Keywords}

\section{Leadership and Management, Local Government, Narrative Research, Governance}

\section{Introduction}

"This is the 110-metre hurdles. In a moment hurdles crash; yet one needs to reach the finish line even if all of the hurdles are down. One may not fall down before the finish line is crossed. However, the time is taken."

Chief executive officer of a medium-sized municipality.

This article investigates the transformation of local government leadership as a change in interaction. Traditional interaction patterns are challenged by the increasing complexity of governance relations. We shall show that there is an important transformation-in both the quality and quantity-of interaction; a change that requires new skills and new interaction patterns from local leaders.

Instead of focusing on mayors, we focus on chief executive officers (CEOs), the highest civil servants in Fin- 
nish local government. We take as granted that the operational environment of local leadership has changed in consequence of the increased complexity of governance relations (see Laffin, 2009: p. 22). We want, however, to obtain a better understanding of how local leadership has changed. The research question is: How is the increased complexity seen in interaction needs and patterns and how does this affect the work of a municipal CEO?

Our article contributes not only to the debate on local leadership but also to the debate on governance, with its discussion of the "messy" nature of present-day public governing, and with the development and implementation of public policy through interaction between different societal actors (see Rhodes, 1999; Jessop, 2000; Peters, 2002; Peters \& Pierre, 2000; Kickert et al., 1997; Milward et al., 1993; John, 2001). But while most of the literature on governance explores questions of inter-organizational structures, we examine how local leaders—as actors in different networks-interpret changes in governance relations as part of their leadership environment. Governance theory has underlined the complexity of societies and the management of inter-organizational networks, but it has paid little attention to the dynamics between intra-organizational and inter-organizational relations.

The empirical analysis is based on biographical narratives of very experienced (born in 1945-1950) Finnish municipal chief executive officers. The narratives form a rich set of interpretations about the changes that have occurred in the role of municipalities during the last four decades. The narratives also give a wide variety of descriptions about the current role and patterns of interaction in the leadership work of local executives. In addition, our empirical data offer interesting explanations of crucial factors underlying the observed leadership changes.

Examination of how the Finnish municipal CEOs describe important changes in their leadership environment reveals in-depth familiarity with current international discourses on network governance, the role of the state, citizen and markets, and the fragmented nature of politics and administration. The aim of this paper is to explore how the transformation of local government leadership influences on interaction, and what kind of changes can be detected.

This paper is significant by providing an interpretative sight to changes happened by those who have lived along local leadership transformation during the past decades. The data were collected from one country and are thus bound to a specific cultural context. It is justified, however, to suppose, that the narratives of Finnish municipal CEOs can both support and increase wider theoretical understanding concerning local leadership change while also providing interpretations of and explanations for a phenomenon that is basically international.

\section{Local Leadership as Interaction in Governance Relations}

According to a very generic definition, leadership can be understood as influence over others. The leader aspires to influence people to act in that way that culminates in the fulfillment of the goals of an organization (Yukl, 2010; Northouse, 2007: p. 3). In this conventional way of thinking, the core of leadership is about defining the direction, influencing actions, moving things and people, and avoiding inertia. But leadership entails much more: it is a complex social phenomenon (Bennis, 1959) that is vague in substance or limits (Pedersen \& Hartley, 2008) and is always affected by its context (Hersey \& Blanchard, 1988). Recent leadership literature has highlighted both heroic individual leadership (Milner \& Joyce, 2005) and shared leadership (Pearce \& Conger, 2003; Wister et al., 2014), reflecting the diverse and complex nature of the phenomenon. The emerging complexity leadership theory has pointed that social processes are too uncontrolled to be attributed either to a single individual or to pre-planned processes (Finkelstein, 2002; Lichtenstein et al., 2006).

There is much literature on public sector leadership. A good deal of this literature is fairly generic and seems to assume that public sector leadership is leadership regardless of the administrative level, organization or scope of the activity. We argue that municipal leadership is unlike any other; that a municipal CEO works in a very special environment affected by many complex governance relations (Siegel, 2010: p. 140).

The context of local leadership is changing essentially. According to Liddle (2010: p. 658), the current dynamic and complex multi-agency environment of public leaders has rendered many established theories obsolete, as "inappropriate explanatory models of complex realities." Organization theory has long emphasized the organization's relation to its environment and leaders' action at interfaces (Katz \& Kahn, 1966). For some time, this phenomenon has been clearly visible in public sector organizations and local government, too. On the one hand, this development can be seen as the change from traditional administration to new public management, and on the other hand as moving towards new public governance (Osborne, 2006, 2009). Today, local leadership takes place more or less in the framework of governance, a concept referring to the new process of governing, 
the changed condition of ordered rule and the new tools with which societies are governed (Rhodes, 1996: pp. 652-653).

There is no uniform governance theory, only a number of variations and different sub-concepts (Schneider, 2012; Klijn, 2008). The core idea of governance is that hierarchical relations are being replaced by long-term network-type relationships between key individuals located in a diverse set of organizations. Boundaries within the public sector as well as between the public, private and third sectors are blurred. Public policy is planned and implemented in interaction between different actors, and these interactions are based on dependencies, trust and the exchange of information (Rhodes, 1999; Jessop, 2000; Peters, 2002; Peters \& Pierre, 2000; Kickert et al., 1997; Milward et al., 1993; John, 2001).

In the framework of governance, a municipality can be seen as a part of an interaction network made up of multiple actors. A municipality cannot act independently or detached from other actors, but acts rather in close interaction with different actors, both horizontally and vertically. Governance theory highlights the municipality's communal and network character. The work of local leaders is not limited to municipal organization. In the handling of tasks, it is important to cooperate with many actors, even those weakly bonded to the municipality locally and supra-locally.

In our interpretation, governance framework specifically means network governance (see Rhodes, 1999; Klijn, 2008) highlighting the importance of trust and reciprocity in building and sustaining long-term relations (Kickert et al., 1997).

From the governance perspective, it is understandable that many of the newer perceptions of leadership emphasize interaction as the foundation pillar for the leader's work. As Pedersen and Hartley (2008: pp. 334-335) point out, the spaces for public leaders are created at the interface between boundaries of the public and the private, politics and administration, the citizen and delivery, and thus leadership is essentially about "communicating strategically".

Siegel (2010) analyzed the role of the municipal chief administrative officer (CAO) in a context that shares many useful elements with our approach. The municipal civil servant, as many other managers, must lead in three directions (Mintzberg, 1997; Siegel, 2010). The traditional leading down refers to relations with subordinates in the organization. Leading out refers to relations with important stakeholders who, though not belonging to the municipal organization, are nonetheless extremely important players in the system as a whole. Leading up describes relations with the political organization of a municipality, the council and the executive board. Siegel (2010: pp. 159-160) considers the work of a municipal civil servant unique in the way the different leading directions must be handled. According to his study, the municipal CAO must remain separate from electoral politics but must also be politically sensitive as well as operationally oriented, and at the same time involved in the politics of governing society.

We know that the work of a municipal CEO is challenging. One factor impacting on these challenges is the very vast scope of municipal tasks. The highest municipal civil servant has the difficult job of creating a comprehensible entity from a sometimes quite fragmented and substantially complex ensemble. The job is challenging in part because of the number of governance relations present. If the job merely involved taking care of the organizational level of a municipality, it would be much easier. In addition to the conventional governance relations, which include the personnel and customers, the municipal CEO handles relations with politicians, local and regional companies, and with citizens to name just a few (Siegel, 2010: p. 159).

The Finnish municipal CEO system differs from the international references because of the strong position of the highest municipal civil servant, which is close to that of a mayor. Instead of their formal position and managing tools, the CEOs' work and leadership are based on personal and social influence on people. Municipal CEOs do not have directional power over municipal politicians, who make the final decisions. In consequence, maintaining balance and negotiating are important, but often complex, fields of leadership. The municipal CEO's role is limited within the interfaces between the preparation and making of decisions, and falls between the administration and politics.

\section{Narratives as Research Material}

This article applies narrative analysis complemented with biographical perspectives. The approach is based on a view according to which people deal with their experiences by telling stories. Through the stories, people give meanings to actions, events and phenomena, and analyze their experiences by linking them to larger and more 
generic sagas, tales and stories. Narratives allow cultural learning and function as the knowledge reserve of a community, even a society. Narratives can be used to discern past events, even a life as it has been lived. In this case, narratives reflect on local government leadership. The narrative approach allows the storyteller to observe past actions and events from a different point of view. Sometimes narratives can be seen as metaphors for social change, or they can produce parallel interpretations of crucial events in a society (see, e.g. Sarbin, 2004; Bruner, 1990).

This study is based on the narratives of 17 very experienced Finnish municipal chief executive officers. These municipal CEOs, born between 1945 and 1950, belong to the Baby Boom Generation. In total, these 17 leaders have held various positions in more than 100 municipalities and have worked as CEOs in approximately 50 different municipalities. The interviews took place in December 2012 and January 2013. At that time the interviewees were either still active in working life or had recently retired. They were selected by discretionary sampling. The criteria were their date of birth and their long experience as a municipal CEO. In order to ensure a reasonable mix of different types of local authorities and leaders with varying backgrounds, we emphasized the heterogeneity of the sample (men women, rural-urban areas, different political backgrounds and various parts of the country).

The reason for focusing on this group's experiences is their long careers in municipal management. They have been able to follow the evolution of Finnish society for several decades. They have seen various phases, phenomena and stages of development all the way from 1970s up to the present day. Their years of experience have produced multiple views concerning the Finnish welfare society and municipal management, including the changes that have occurred in the work of municipal managers. Their social reserves of anecdotes encompass tacit knowledge and vision through which the development and current state of municipal management can be structured and analyzed.

The interviews were conducted and the narratives were gathered with a light thematic approach. The interviewees were encouraged to be frank when sharing their experiences about their life and work as municipal CEOs. The results were astounding: the interviews were full of vivid descriptions of actions, events, persons and insights as well as in-depth analysis of the changes affecting their leadership and municipal life as a whole.

By applying a narrative approach and a wide thematic frame, it was possible to identify poignant features and factors that were key elements of change in the municipal managers' work. In these stories, experiences gained over different time periods and in different places blend together and are, in many respects, collective. The life stories combine the municipal CEOs' subjective experiences into larger development cycles of local government and leadership. The stories reveal how certain events developed, what the causes and consequences of these events were, and how different developments and turning points are linked together. Through these stories the chief executives also construct and reconstruct their identity as local leaders.

Storytelling has a constructive role. Stories and narratives provide an opportunity to produce new interpretations, even to create new organizational or institutional identities (see Manuti \& Mininni, 2013). The stories we heard were very reflective-the saga of the role of local government in society intertwined with the stories of individual personal growth as a leader. The story of reinventing local government supported the story of leadership development. The basic orientation in the stories was transformation: the transformation of the municipality, the transformation of a society, and the transformation of leadership and the tools used in the local leader's everyday work. The collected narratives vividly described the paths of change and the essential phases of the evolution of municipal life in Finland. In addition, the leaders also deeply analyzed the global trends seen in the transformation of Finnish society at large.

Next we present our analysis, drawing on the narratives that show that both the quality and quantity of interaction have changed. To facilitate structuring the narratives on interaction, we place them in different governance relations. Interaction takes place on the fringes and in the relations, so the changes are seen most clearly in the relations as well.

\section{The Narratives on Leadership Transformation: From the Creator of Long-Standing Relationships to an Interactive All-Rounder}

The 17 municipal CEOs interviewed for our research tell stories on local leadership in the midst of societal changes and as part of the transformation of the Nordic model of local government. Their stories begin in the 1970s and continue to the present day. The role of municipalities in Finland has changed in many ways, but the 
main thread of change is a shift from the "golden days" of municipalities to the more chaotic state that exists today. The construction and development of the Finnish welfare society was followed by the golden days of "the active 1980s", a time when municipalities and local government enjoyed favourable development and active local politics; the era when municipal managers of the Baby Boom Generation took up their first leadership responsibilities, paving the way for their positions and laying the foundation for their professional development as leaders. The favourable attitudes towards development and a steadily improving economy enabled the municipal managers of this period to develop their role in the desired direction, for example in line with their local economic development policy interests.

Unfortunately, these "golden days" ended abruptly with the recession of the 1990s. At that time the social role of municipalities became more prominent, and activities became focused on ensuring the well-being of citizens and supporting the weakened business sector. During the period of growth that followed the recession, it was particularly vital to shoulder responsibility and ensure favorable conditions for development. In the 2000s, the position of municipalities has become increasingly challenging, even chaotic, in many ways.

The municipal CEOs identify four important changes in their governance relations. These are summarized in the following narratives: the narrative on the dissolution of municipal boundaries; the narrative on the cooled relations between the State and municipalities; the narrative on municipal inhabitants' changing role from participatory residents to exacting customers; and the narrative on the fragmentation of local politics.

These four narratives describe how complexity is seen in the everyday practices of local government, how interaction needs increase, how the nature of interaction changes and how these factors challenge local leadership. The changes appear to be fairly straightforward in the narratives; in the past things were one way and now they are another way. The changes are not pinpointed to some specific moments or connected to simple explanatory factors.

\subsection{The Dissolution of Municipal Boundaries Highlights Horizontal Governance Relations}

The dissolution of municipal boundaries describes the decline in the importance of administrative (intermunicipal) and institutional (public-private-third sector) boundaries. The field in which local authorities seek to carry out their tasks is rescaled and remixed. The boundaries between different actors are dynamic and unstable. This change has shifted the focus from intermunicipal matters towards municipalities' position and interaction in relation to the surrounding society.

"When I started in Keitele in 1980, it was mainly dealing with decision-making in the local council and municipal organization. In a way, the outer world was somewhere there... Now, the municipality is more like a knot in local actors' network. Earlier, it was more limited to the boundaries of local government, and the services." Interview K

Cross-boundary activities are seen as a gradual learning process. It is a question of finding and building a new kind of leadership, and consolidating approaches and practices to support this new leadership. It is essential to build understanding between different actors, Active, effective cooperation among civil servants and politicians is necessary; in addition, confrontation and distrust between cooperation partners must be reduced. Accordingly, the organization of services between the public, private and third sectors requires a reinforced mutual understanding of the operating logic and approaches of different parties.

From the perspective of leadership, the dissolution of boundaries means that municipal CEOs need to direct their energy increasingly to horizontal governance relations. This change brings a vast increase in the need for interaction between municipalities, and with municipalities, companies and the third sector. The change affects municipal leadership and, for example, it complicates the management of services. The implementation of tasks that had previously been taken care of within one's own organization now requires much interaction. The dissolution of municipal boundaries has narrowed the space of leadership. Some municipal CEO's actions that in the past had been taken on the basis of authority have shifted to become leadership through influence.

\subsection{Cooled Relations between the State and Municipalities Diminish Predictability}

Relations between the State and municipalities have cooled. In the 1980s municipalities and the State still stood on the same side. They worked together to create wellbeing in different municipalities throughout the country despite their differing operating logics. Relations between municipalities and the State were handled with care. 
Municipal CEOs had their own contact persons in central government. Both partners invested much time and effort so that these relations would be confidential and durable. Particularly during the past decade this situation appears to have changed essentially; both institutional and personal relations have cooled down.

At the individual level, these relations appear more formal and contextual than before. The long visits to municipalities made by central government officials, lasting several days and including long dinners and evenings in the sauna, are history. So, too, are visits to Helsinki, the capital, by delegations of municipal leaders. Personal relations are no longer appreciated, and there is no time for them. Both sides are also afraid that entertaining and hospitality will be interpreted as corruption or an attempt thereof.

"As we noted, we have common acquaintances and friends... It makes it easier, it kind of takes shortcuts. If you have been able to be in informal contact. For example, if you go skiing for three days together, you have been together from evening to night, to morning and to the next day. Then you have noticed whether or not you share some kind of common thoughts with that person.” Interview B

At the institutional level, the State is considered to have withdrawn from cooperation with regard to the development of welfare and the local economy. Nonetheless, when it comes to steering the production of services, the State is seen as eager to control municipalities through very detailed regulation. The State's actions in the latest reform process are seen as being so straightforward that there has been neither time nor space for interaction between municipal CEOs, local politicians and central administration. The reform process is experienced as the one-way implementation of top-down plans, or even as dictation.

This change has affected both the amount and the nature of interaction. Municipal CEOs do not have the same trustful link with central government actors that they had before. Government officials had previously been seen as civil servant colleagues who were struggling with the same kinds of issues and challenges, but on a different scale. Now it seems that collegiality has crumbled to some extent, partly because of State-level reforms and changes and because of the change in the State's political steering. Government officials' role in the central government system has also changed and municipal CEOs cannot be sure where or in whose hands the power rests in different situations.

\subsection{Inhabitants' Changed Role Appears Ambivalent}

Inhabitants' role is seen as changing from participatory residents to exacting customers. They have adapted a new role as consumers and customers of ready-made services. These "inhabitants of new era" critically judge municipal facilities and services, are more demanding and are aware of their rights. A higher level of education is one explanation for their improved knowledge of their rights. However, the level of education does not seem to enhance their sense of responsibility with regard to common issues.

"There are lots of lawyers and engineers living there. They know their rights very well. And they are able to... They know how to advocate for their rights really loudly. They know their rights, but sometimes... it is not clear whether they know what their responsibilities are." Interview $C$

Consumer status and being in a customer relationship with the municipality mean that inhabitants are withdrawing from the common responsibility for the community's wellbeing that they bore earlier. Local politics is not attractive as it used to be; the provision of services and taking care of the local community are left for professionals or professional politicians to handle.

The change in municipal inhabitants' role impacts on the need for interaction in municipal leadership. An increasingly smaller share of interaction takes place through the indirect representational system while a greater share takes place outside it through, e.g. service organizations (customer-oriented approaches), social movements (pro-movements) and both traditional and electronic media.

Electronic media in particular call for new skills and new approaches. Earlier, and even in the 1980s, the work was dominated by agendas and information was shared with the media and stakeholders only after decisions had been made. Today, publicity is an integral element of the entire politico-administrative process. The media thus affects preparation, decision-making and leadership all the time.

The changing role of municipal inhabitants is considered to include contradictory elements. On the one hand inhabitants are seen to take less responsibility as residents while on the other hand they use more channels of influence to present their demands. They also actively approach the municipality concerning their special needs 
and as a client using services. This change can be seen as opening municipal politics. Inhabitants are in touch with the municipality more through services. They demand more and no longer accept services that are the outcome of administrative logics or poor quality.

\subsection{Fragmented Local Politics Fades out Power Coalitions}

Local politics have become fragmented. The influence of political elites and regimes has decreased and been replaced by populist culture. Features of this new culture include the rise of movements focused on a single cause, an emphasis on short-term goals, a weakened sense of responsibility, the dissolution of party political ideologies, and increased media publicity. Populist culture stresses the present day and concrete events at the expense of long-term plans and investments, and thus hampers building for the future.

In most municipalities decision-making used to be based on certain prevailing political coalitions and the activities of regimes. At that time, the municipal CEO had to negotiate with only two or three the most influential politicians to reach agreement on matters. These prevailing groups created a stable, long-term and predictable political culture through their actions. At the same time, they made the municipal CEO's work simple because the CEOs knew who to approach in order to decide things and what sort of influence was needed.

When local power coalitions started to break down, the space for leadership decreased. Decisions and negotiating coalitions were directed by situational aspects, if negotiations were possible at all before decision-making itself. The importance of influence became highlighted because the negotiation partners were no longer predetermined according to the traditional power coalitions of local elites; instead, they became more situational.

"Even the political parties are internally fragmented. The logic is not shared, and it is difficult to know what is the ideology that people rely on... if they rely on any. It seems to be quite short-sighted, and sometimes I feel that the local politicians are also somehow, how I should put it, somehow 'lost'." Interview C

In addition to many other problems, the jerkiness of the new political culture hampers the CEO’s ability to act at the other important interfaces of local governance relations, especially in cooperation with other municipalities and enterprises. It is difficult to negotiate and create trusting external relationships if internal politics produces surprises every day.

However, the transformation of municipal politics is not seen as totally destructive. The novel set-up has given room for a new kind of cooperation and innovation, making it possible to solve local issues through new, emergent and sometimes wider forums and platforms.

\subsection{Leadership as Interaction in Governance Relations}

In our study the municipal chief executive officers regard local leadership as interaction that takes place in governance relations. This interaction is largely a set of balancing acts. Balancing is needed between internal and external governance relations or among different interest groups, with local residents, central government, the media and politics. Interactive leadership utilizes different opinions and views, and is adaptive in the sense that participating actors often have to reconcile their goals and visions. The future does not appear similar to everyone, and interaction makes it possible to create interpretations of different options and new paths. It does not prevent conflicts, but rather uses them as a resource for critical openings and reform ideas.

Interaction is also considered one of the most important tools for expanding the scope within which municipal managers operate. Restricting factors, such as central government control or the municipality's particular economic status, can be counterbalanced through various modes of operation and leadership qualities, thereby enabling municipal leaders to create a broader scope of operation.

Leadership is not only dealing with the organization, nor is it merely taking care of outer relations or exerting influence within networks. Leadership in the context of local authority means actions occurring in balance between as internal and external governance relations.

An example of a balancing act is a situation where the CEO builds networks for strengthening local economic development in a way that calls from major investments from the municipality. While working closely with external governance relations, the CEO has to confirm support for the investments from his own staff and from politicians as well as also ensuring acceptance by local citizens and the media. Maintaining balance requires interaction between politics and administration, between the municipality's finances and needs, and between societal change and the role of local government. The spaces for leadership are determined on these surfaces via 
interaction, and leadership positions are produced through interaction in governance relations.

There are many interaction planes, some of which involve more tension than others. But what makes the situation wicked is the notion that the scale and scope of interaction required is "getting out of hand" and the nature of interaction itself is transforming rapidly. According to a common thread in the four narratives, both the quantity and quality of interaction have changed so that there are more and more planes at which interaction is needed, but at the same time the quality of interaction is altering.

The quantitative increase of interaction is one of the direct consequences of the increased number and complexity of governance relations, which stem from the four changes described above. New interfaces have arisen between municipalities, enterprises and the third sector and within municipal key actors, the media and municipal inhabitants.

The work of public leaders, particularly that of municipal managers and city mayors, has always required much interaction because of the wide scope of tasks and the many stakeholder groups associated with them. Local political groups, residents, local entrepreneurs and businesses, and central administration have traditionally been important stakeholders to municipal leaders. Every one of these groups includes tens and even hundreds of different interaction interfaces. But the narratives of the Baby Boom Generation leaders describe a phenomenon that could be defined as an explosion of interaction needs.

Earlier, a leader faced a hectic atmosphere momentarily, for example in actions related to local economic development. Even during hectic moments, things were more straightforward and easier to govern. Now, the fragmentation of local politics has forced local leaders to interact in new and unstable coalitions and to seek support in a decision-specific way in order to pave the way for decisions. The increase of interaction in governance relations is difficult to describe mathematically with precision-nor would this make sense, because the situation varies in each municipality and in time-but according to the narratives, the amount has grown significantly, even exploded.

Many narratives link the changes in interaction not only to governance relations but also to the development of communication technology, the altered role of inhabitants, and communication culture. In this new communication culture, face to face meetings are not as popular as before. Technological development has made it easier to communicate independently of time and space. People communicate 24/7 because they consider it possible and because they carry their communication devices with them, even in the evenings and during weekends.

Citizens now have a lower threshold for sending email or text messages or for calling. They communicate when they face a situation that in their view requires a leader's attention. Some inhabitants also expect an instant reply. In this kind of situation, it is not easy for a leader to step aside from the information flow and make a distinction between work and leisure.

The increased quantity of interaction and more numerous possibilities enabled by new technology still haven't led to qualitative improvements in interaction. Municipal CEOs interpret the situation to be the opposite. Interactive relations are not necessarily built with any long-term intent but occasionally, readily and situationally. To an increasing extent, interaction is "instant interaction" that brings people together to solve a certain problem, or some external challenge pushes people to hold a couple of quick meetings in order to reach an instant solution. It is not even necessary to meet face to face; the meetings can take place via videoconference, e-mail or telephone. Communication is different than before, when it was based on personal, often long-term, meetings. Coalitions change rapidly and there is too little time to get to know each other personally, or people don't want to do so. The most important characteristics seem to be speed and short-time effectiveness.

The change becomes visible when the present is compared to the "golden days" of 1980s, referred to above. According to the municipal CEOs, at that time their interaction skills and cooperative knowledge supported success in their work as a leader. Their narratives indicate that there was enough time to take care of tasks and relations. Municipal CEOs, public servants and politicians were not forced to do everything as quickly as possible; there was time to sit down, prepare and have a proper discussion in different groups with a view to improving participation.

"Personal good relations were built through longer visits (with negotiations in saunas, etc.). People became friends. And visits were made on both sides. One didn't have to work hard to attract visitors, when you just called and said: 'Would you like to come, I will organize a nice...' 'Yes definitely' 'How about fishing?’ Some liked fishing, others wanted to hunt.” Interview K.

The leaders say it is important to pay attention to survival skills, which are needed to cope with the informa- 
tion flood. Owing to the vast scope of interaction, it is necessary to prioritize time management and to define the surfaces which are necessary for handling the fundamental tasks. It is not possible to act with same intensity at every interaction interface.

Instant interaction entails more situational awareness, social skills and quicker response. Self-knowledge and social capital can also help to expand the scope in which experienced municipal managers operate. Other useful competences are the ability to prioritize and time management, the ability to identify what is necessary, a rapid absorption capacity, ability to process information, good argumentation, social competence and interpersonal skills.

The new ways of interaction mean that knowledge and different, competing views are available in a way completely different to that in the early days of the leaders' career. For a leader, it is increasingly important to be able to process and compress information. Politicians, for example, wait for clear and sometimes seamlessly justified motions in order to make decisions. Leadership is—even more than before—defined by the ability to make choices and to extract the most relevant issues for further processing.

"In municipal leadership one has to be able to compress things to a certain outlook. It needs a lot of skill. It is not easy when so much information and so many competing views are available. And then these interpersonal skills, they are important. Life is more open and interactive than before. Getting along with people is important." Interview $K$

In the leadership narratives, interaction ability is not about management techniques or know-how gained from management textbooks; it is a mix of experience and knowledge, "a situational awareness and sense of rhythm" that has been achieved over the course of time. According to one CEO, it is like a long marriage: "you know from your spouse's face whether she is in a good or bad mood”. In leadership, experience and self-confidence, trust in one's own competencies, surface as an essential resource.

Very often the narratives end up in reflection on how the leader sees people. In most of the stories, the municipal leaders experience working with people in a positive way. In fact, the most positive experiences of municipal leadership are associated with interaction. The overall positive sentiment leads to the conclusion that interaction is not seen as a burden, but that leaders also get a lot out of their interactions; interaction gives motivation, feedback and a sense of meaning. Leaders don't listen to people or discuss issues with people because management textbooks instruct them to do so, making interaction with people a learned management technology; leaders interact with people because they like to do so.

"A municipal leader has to like people, to be interested in them. You get something, always, when you deal with people. I experience it not as a burden but as enriching." Interview $N$

Interactive leadership is partly a question of skills and knowledge, but it is equally as much about personality. In the leadership narratives one can see the "ideal leader" who is patient and who has the ability and desire to interact. The narratives include descriptions where leaders actively try to make themselves easily approachable and humane, to avoid the problems caused by hierarchies and distance to power. Interaction is considered to be the most valuable tool when one aims at widening the spaces for leadership. Interaction is so valuable that the leaders have invested time in it. None of the leaders consider themselves interaction professionals in the early stages of their career, but all of them describe an increase in interaction abilities during their careers.

"I started building the... I didn't want to be distant, but laid back and with a sense of humor. I'm not a big comedian during coffee breaks, but make fun of myself and my mistakes. 'I did it again, blew the whole thing!' I try to be a normal person. I feel that it is appreciated." Interview A

\section{Explosion of Interaction Needs and Emergence of Instant Interaction- Implications for Local Leadership and Governance Theory}

A starting point for this study was the idea that studying local leaders' narratives on their interaction interfaces, and the changes that occur there, would contribute to the knowledge on changes in leadership and would generate a tentative theory on interactive local leadership within governance framework.

The narratives of local leaders paint a picture of local leadership as interaction in governance relations. Local leadership differs from leadership in many other comparable organizations, even public ones. Local leadership is less about formal power but more about influence. Influence and interaction are shown to be the very core elements of local leadership. The leadership is mostly constructed in relation to stakeholders and people over whom 
the leaders have no legitimate authority: residents; local politicians; local companies; other municipalities. The importance of influence brings interaction into the heart of local leadership. To be able to exert influence, one has to be able to communicate and interact.

The narratives also tell about the increasingly hectic, dynamic and multidimensional context of leadership. Formally defined relations have been replaced by self-constituting ones. Today, neither the value sets previously known by professionals nor laws are the strongest arguments underpinning decisions, and the whole position of a leader is partly created via negotiated relations in network-like structures (see also Pedersen \& Hartley, 2008: p. 335). As Liddle $(2003,2010)$ has stated, leaders work in strange territories, beyond traditional boundaries and seek to make sense of new situations and dynamic policy shifts. Theoretically, the explosion in interaction needs in internal as well as external governance relations challenges governance theories' ability to explain the realities of local leaders. When this image is added the qualitative change of interaction, the situation becomes even more confusing.

Local leadership is interaction, which takes place at the interfaces of internal and external governance relations with the aim of handling the core mission of the municipality. The narratives on changes on these interfaces - on the explosion of interaction needs and the qualitative changes — can be interpreted as a signal of the opening up of local government. The narratives are stories of a more transparent and more open municipal decision-making culture, where decisions are not predetermined by small elites and where even citizens participate in discussions with the help of new technologies. They also paint the picture of a "hectic society" and instant interaction, where decision-makers try to handle issues that emerge as soon as possible, sometimes with qualitatively poorer information and interaction than before.

The idea of instant interaction seems to be in conflict with some basic propositions of governance theory, particularly those dealing with the nature of network relations. Governance theory stresses networks and interdependencies, equality, and long-term relationships based on trust and information exchange as basic features of the new (post-modern) society. According to the narratives reported here, interaction events are not only situational and dynamic, but also rapid and even superficial. Interaction during these meetings does not easily enable creation of the trust needed in network-type work, not to mention long-term durable relations. Moreover, the explosion of interaction needs is a clear challenge to network building because there is no time to invest in all of the important networks. New technical communication devices help only slightly. In the past, local leaders used to have much more time to prepare things, to meet other actors, and to build the mutual understanding and trust needed for major decisions.

On the other hand, the lower threshold to communication has somehow opened up the municipal entity. Information is received from many sources and even real-life know-how can impact on decisions if it is channeled efficiently, for example via social media.

The conclusions on the quantitative change in interaction needs are quite straightforward. More and more interaction is needed in the work of a municipal CEO. This requires new skills in both communication patterns and contents. The growing amount of communication does not make it easy for municipal CEOs to get their message across. The ability to prioritize what to communicate with whom, the ability to identify what is necessary, and the ability to process information rise above many other skills. Knowledge of municipal affairs naturally serves as a basis for a rapid absorption capacity and helps the leader to choose the most important planes for action.

The picture is not that clear when it comes to the quality of interaction. Long term relationships have partly been replaced by temporary, context-specific and matter-sensitive groups. Interaction has become increasingly instant in nature: the leader is supposed to communicate regardless of time or place. The change in interaction suggests that leadership is based increasingly often on situational awareness, a sense of rhythm and powerful oratory. These are skills traditionally associated with politicians. Studying the transformation in the local level interaction reveals a trend where the traditional roles of the dualistic local level leaders intermingle. This is in line with the idea of the political bureaucrat presented by Siegel (2010). It is required that politicians have more and more substance knowledge while the municipal CEO is changing from a task-oriented manager, or a classical bureaucrat, to a relationship-oriented leader or political bureaucrat.

\section{Concluding Remarks}

The narratives indicate that the quality and quantity of interaction have changed remarkably, bringing new tensions to leadership work, new challenges to the traditional role of a municipal CEO, and new insights into local 
leadership and governance theory. The instant nature of interaction opens up a window for analysis of a real transformation in both interaction patterns and communication culture-a transformation that clearly challenges local leadership.

In demonstrating that most of the Finnish local government leaders function outside the scope of formal authority, this research emphasizes the notion that local leadership is about influence and interaction. The municipal CEOs of the Baby Boom Generation paint a picture of local leadership as interaction that takes place in intra-organizational and inter-organizational governance relations. The leader can use interaction as a tool for balancing and strategizing acts and for expanding his managerial latitude. Interaction and successful communication can also be a rewarding resource, helping leadership to evolve and develop constantly.

Our generalizations about the changing interaction and leadership are naturally tentative, since different external and internal stakeholders matter differently for various types of local leaders. These findings encourage more empirical research on the theme of local leadership as interaction in governance relations as well as the development of a better theory on the change in interaction patterns in local governance. Is the current local leadership really "encounters in events characterized by instant interaction" as the Baby Boom Generation leaders indicate in their narratives; an activity where coalitions are changing fast and where there is no place to build up the trust needed to form mutual understanding or take care of difficult decisions?

The age of the studied leaders can offer one possible explanation for the experienced qualitative change in interaction; aged municipal CEOs do not necessarily master the new communication technology as efficiently as younger generations and they don't feel they need it all the time. They are not voluntarily hooked on the flow of information, for example being available in social media 24/7. In addition, many of their trusted friends have already left working life, which means that the municipal CEOs have lost an important part of their daily networks.

If the qualitative and quantitative change in interaction is a broader phenomenon, not merely a change in the context of this study, many further questions must be addressed. The most essential is perhaps the question on the nature and practices of leadership in situation involving instant interactions. How do leaders act proactively when the need for interaction explodes? How can one act sustainably in events determined by instant interaction and how is trust created and maintained?

\section{References}

Bennis, W. G. (1959). Leadership Theory and Administrative Behavior: The Problem of Authority. Administrative Science Quarterly, 4, 259-301. http://dx.doi.org/10.2307/2390911

Bruner, J. (1990). Acts of Meaning. Cambridge: Harvard University Press.

Finkelstein, S. (2002). Planning in Organizations: One Vote for Complexity. In F. Yammarino, \& F. Dansereua (Eds.), Multi-Level Issues in Organizational Behavior and Processes (pp. 73-80). Bingley: Emerald Group Publishing.

http://dx.doi.org/10.1016/s1475-9144(02)01028-7

Hersey, P., \& Blanchard, K. H. (1988). Management and Organizational Behavior. Englewood Cliffs, NJ: Prentice-Hall.

Jessop, B. (2000). The Future of Capitalist State. Cambridge: Polity Press.

John, P. (2001). Local Governance in Western Europe. London: SAGE Publications.

Katz, D., \& Kahn, R. J. (1966). The Social Psychology of Organizations. New York, NY: Wiley.

Kickert, W. J. M., Klijn, E.-H., \& Koppenjahn, J. F. M. (1997). Managing Complex Networks. Strategies for the Public Sector. London: SAGE Publications.

Klijn, E. H. (2008). Governance and Governance Networks in Europe. An Assessment of Ten Years of Research on the Theme. Public Management Review, 10, 505-525. http://dx.doi.org/10.1080/14719030802263954

Laffin, M. (2009). Central-Local Relations in an Era of Goverance: Towards a New Research Agenda. Local Government Studies, 35, 21-37. http://dx.doi.org/10.1080/03003930802574698

Lichtenstein, B. B., Uhl-Bien, M., Russ, M., Seers, A., \& Orton, J. D. (2006). Complexity Leadership Theory: An Interactive Perspective on Leading in Complex Adaptive Systems. Emergence: Complexity and Organization, 8, 2-12.

Liddle, J. (2003). A Regional Regime. PhD Dissertation, Coventry: University of Warwick.

Liddle, J. (2010). Twenty-First-Century Public Leadership within Complex Governance Systems: Some Reflections. Policy \& Politics, 38, 657-663.

Manuti, A., \& Mininni, G. (2013). Narrating Organizational Change: An Applied Psycholinguistic Perspective on Organiza- 
tional Identity. Text \& Talk, 33, 213-232.

Milner, E., \& Joyce, P. (2005). Lessons in Leadership: Meeting the Challenges of Public Service Management. Abingdon: Routledge.

Milward, H. B., Provan, K. G., \& Else, B. A. (1993). What Does the "Hollow State” Look Like? In B. Bozeman (Ed.), Public Management: The State of the Art (pp. 309-322). San Francisco, CA: Jossey-Bass.

Mintzberg, H. (1997). Managing on the Edges. International Journal of Public Sector Management, 10, 131-153. http://dx.doi.org/10.1108/09513559710166020

Northouse, P. G. (2007). Leadership, Theory and Practice (4th ed.). Thousand Oaks, CA: Sage Publications.

Osborne, S. (2006). The New Public Governance? Public Management Review, 8, 377-387. http://dx.doi.org/10.1080/14719030600853022

Osborne, S. (2009). The New Public Governance? Emerging Perspectives on the Theory and Practice of Public Governance. London: Routledge.

Pearce, C. L., \& Conger, J. A. (2003). Shared Leadership: Reframing the Hows and Whys of Leadership. Thousand Oaks, CA: Sage

Pedersen, D., \& Hartley, J. (2008). The Changing Context of Public Leadership and Management. International Journal of Public Sector Management, 21, 327-339. http://dx.doi.org/10.1108/09513550810880214

Peters, G., \& Pierre, J. (Eds.) (2000). Governance, Politics and the State. Basingstoke: Macmillan.

Peters, G. (2002). The Changing Nature of Public Administration: From Easy Answers to Hard Questions. Asian Journal of Public Administration, 24, 153-183. http://dx.doi.org/10.1080/02598272.2002.10800399

Rhodes, R. (1999). Governance and Public Administration. In J. Pierre (Ed.), Debating Governance (pp. 1-54). Oxford: Oxford University Press.

Rhodes, R. A. W. (1996). The New Governance: Governing without Government. Political Studies, 44, 652-667. http://dx.doi.org/10.1111/j.1467-9248.1996.tb01747.x

Sarbin, T. R. (2004). The Role of Imagination in Narrative Construction. In C. Daiute, \& C. Lightfoot (Eds.), Narrative Analysis. Studying the Development of Individuals in Society (pp. 5-20). Thousand Oaks, CA: SAGE Publications. http://dx.doi.org/10.4135/9781412985246.n1.1

Schneider, V. (2012). Governance and Complexity. In D. Levi-Faur (Ed.), Oxford Handbook of Governance (pp. 129-142). Oxford: Oxford University Press. http://dx.doi.org/10.1093/oxfordhb/9780199560530.013.0009

Siegel, D. (2010). The Leadership Role of the Municipal Chief Executive Administrative Officer. Canadian Public Administration, 53, 139-161. http://dx.doi.org/10.1111/j.1754-7121.2010.00122.x

Wister, A. V., Beattie, B. L., Gallagher, E. M., Gutman, G. M., Hemingway, D., Reid, R. C., Sinden, D., \& Symes, B. (2014). Effectiveness of a Shared Leadership Model: The British Columbia Network for Aging Research. Administration \& Society, 46, 863-884. http://dx.doi.org/10.1177/0095399712465594

Yukl, G. (2010). Leadership in Organizations. Upper Saddle River, NJ: Pearson. 